
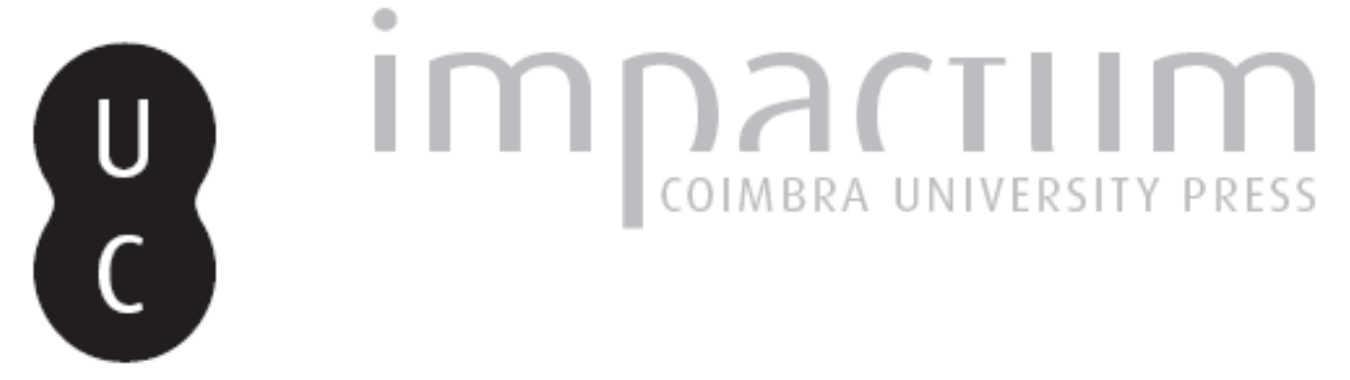

\title{
[Recensão a] GÓMEZ PALLARES, Joan - Edición y comentario de las Inscripciones sobre mosaico de Hispania. Inscripciones no Cristianas
}

Autor(es): $\quad$ Oliveira, Cristina F. de

Publicado por: Imprensa da Universidade de Coimbra

URL persistente:

URI:http://hdl.handle.net/10316.2/45423

DOI:

DOI:https://dx.doi.org/10.14195/1647-8657_37_21

Accessed : $\quad$ 26-Apr-2023 11:42:51

A navegação consulta e descarregamento dos títulos inseridos nas Bibliotecas Digitais UC Digitalis, UC Pombalina e UC Impactum, pressupõem a aceitação plena e sem reservas dos Termos e Condições de Uso destas Bibliotecas Digitais, disponíveis em https://digitalis.uc.pt/pt-pt/termos.

Conforme exposto nos referidos Termos e Condições de Uso, o descarregamento de títulos de acesso restrito requer uma licença válida de autorização devendo o utilizador aceder ao(s) documento(s) a partir de um endereço de IP da instituição detentora da supramencionada licença.

Ao utilizador é apenas permitido o descarregamento para uso pessoal, pelo que o emprego do(s) título(s) descarregado(s) para outro fim, designadamente comercial, carece de autorização do respetivo autor ou editor da obra.

Na medida em que todas as obras da UC Digitalis se encontram protegidas pelo Código do Direito de Autor e Direitos Conexos e demais legislação aplicável, toda a cópia, parcial ou total, deste documento, nos casos em que é legalmente admitida, deverá conter ou fazer-se acompanhar por este aviso.

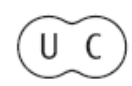


UNIVERSIDADE DE COIMBRA

FACULDADE DE LETRAS

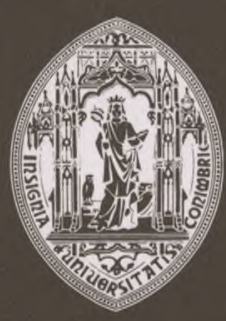

\section{CONIMBRIGA}

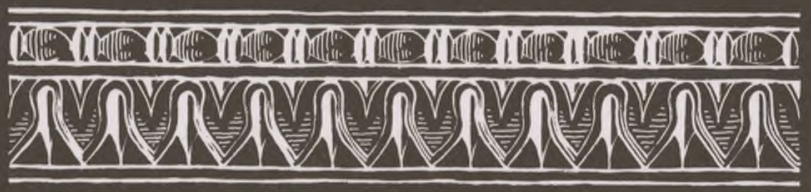

VOLUME XXXVII - 1998 
GÓMEZ PALLARES, Joan - Edición y comentario de las Inscripciones sobre mosaico de Hispania. Inscripciones no Cristianas, Roma, "L’Erma” di Bretschneider,1997.292 pp. ilustr. ISBN. 99-7062-977-5

A obra que tivemos o ensejo de 1er constitui o voi. 87 da colecção Studia Archaeologica e resultou de um projecto elaborado em 1988, nas vésperas do Coloquio Internacional AIEGL, Culto e Sociedad en Occidente a través de la Epigrafia, realizado em Tarragona entre 6 e 8 de Outubro de 1988. A primeira versão da obra estaria pronta em 1992, mas a sua publicação só agora veio a acontecer.

Formado em Filologia Clàssica, Gómez Pallarás assumiu a árdua tarefa de reunir todas as inscrições hispânicas não-cristãs realizadas em suporte musivo, entre o séc. II a. C. e o séc. VITI d. C., perfazendo um total de 83 unidades (73 espanholas e 10 portuguesas). Este Corpus, "atípico", no seu dizer, reúne, pela primeira vez, um conjunto de inscrições ibéricas, gregas e latinas que editou, procurando corrigi-las e interpretá-las, com o auxílio da fonética, da morfologia, da sintaxe e da literatura, ao longo de 200 páginas de texto. Para além do âmbito linguístico, o A. preocupou-se em apresentar o contexto arqueológico dos mosaicos estudados (num micro e macro-espaço), embora o seu desejo de estabelecer uma correlação nem sempre tenha sido alcançado, nomeadamente ao nível da interpretação do macro-espaço, assim como não foi aproveitado para aferir datações.

A obra está organizada em forma de catálogo, ordenado por ordem alfabética a partir das siglas de províncias espanholas, numa primeira parte, e distritos portugueses, numa segunda. Adentro destas divisões, os mosaicos estão arrumados por ordem cronológica. Cada ficha-tipo inclui as seguintes informações: lugar do achado, descrição do local, descrição do pavimento, descrição da inscrição, edição do texto, bibliografia, variantes de leitura, interpretação (com tradução da inscrição) e datação. Nas conclusões, Gómez Pallarès ensaia uma sistematização dos dados recolhidos ao nível da cronologia, distribuição geográfica, contexto (urbano-rural), técnica, num primeiro momento, e relação texto-mosaico, num segundo. Termina com nove afirmações em jeito de síntese: as inscrições em opus tesselatum agrupam-se, maioritariamente, em torno dos séc. III-IV d. C., sobretudo na Hispania Tarraconensis, em meio rural. Na maior parte dos casos, existe uma relação directa entre a iconografia musiva e a inscrição, geralmente presente em locais de comunicação ou habitação e, pelo contrário, inexistente em zonas de passagem ou acesso. Nestas últimas, encontramos inscrições que identificam o proprietário ou o artesão, assim como mensagens admonitórias. As inscrições em opus signinum concentram-se na zona costeira da região acima citada, entre os séc. II a. C. e Id. C.

Finalmente, a obra apresenta um conjunto de índices (lugares de procedência, lugares de conservação, nomes de seres animados latinos, ibéricos e gregos, verba nobis nobiliora) e encerra com as ilustrações fotográficas, num total de 91 estampas.

Conimbriga, 37 (1998) 267-310 
Não há que duvidar da importância do contributo de um filólogo para a ciência arqueológica trazendo preciosas informações de carácter linguístico, utilíssimas quando completadas com um correcto e completo contexto arqueológico que, não foi, aqui, densamente explorado. Pesem embora as conhecidas dificuldades levantadas pela dicotomia inscrição/iconografia, nem sempre evidente ou existente, Gómez Pallarès não fugiu à difícil tarefa da sua análise. Não podemos deixar de mencionar, também, a potencial riqueza do estudo onomástico, nomeadamente ao nível do estatuto social dos vários indivíduos cujos nomes ficaram, ad aeternum, marcados nestes preciosíssimos "tapetes" e que certamente teria enriquecido a obra se Gómez Pallarès não se tivesse cingido meramente à menção da maior, ou menor, frequência dos antropónimos estudados, remetendo o leitor para a bibliografia sobre o assunto. Chamamos particularmente a atenção para a inscrição Ml (Alcalá de Henares-Espanha): ANNIORVM (hedera) HIPPOLYTVS TESSELAV[IT], a propósito da qual Gómez Pallarès aponta o antropònimo Annius como um cognomen (p. 106) quando, na realidade, deve tratar-se de uma das gentes mais frequentes na Península Ibérica (cfr. ILER p. 658), neste caso, proprietária da residência para quem Hippolytus, operário, realizou o mosaico.

Não tendo visto pessoalmente alguns dos mosaicos, Gómez Pallarès fez algumas leituras a partir de fotografias, como ele próprio afirma ( é o caso, por exemplo, de CCI Espanha, do Museu de Cáceres ou de MU5, do Museu Arqueológico Municipal de Cartagena). Não terá sido temerário ? Sê-lo-á, com certeza, em inscrições de leitura duvidosa.

No que se refere à datação das inscrições, ficamos sem saber que critérios foram seguidos: estilísticos, paleográficos, linguísticos, ou outros ? Além disso, data mosaicos que não viu, porque perdidos, e acerca dos quais poucos comentários teceu por falta de elementos, como é o caso de B1, B2, MU6, T2, T3 - Espanha. Também a sucessiva repetição da expressão "villa rural”, para caracterizar as estações arqueológicas, parece-nos desprovida de sentido.

Merece, ainda, uma chamada de atenção a frequente ausência de ligação entre os vários mosaicos citados; nomeadamente a propósito do mosaico de EI Hinojal, Mérida (BA 8 - Espanha), mosaico das estações do ano, o A. refere paralelos fora da Península Ibérica mas não remete para o exemplar de Conimbriga, por ele também abordado (COI - Portugal), onde encontramos a personificação das estações do ano, sem legenda, mas acompanhando também um tema cinegético. Noutro exemplar, proveniente de Mérida (BA 9 - Espanha), a propósito dos equónimos, também não remete para o de Bell-lloc del Pia (GI5- Espanha), Aguilafuente (SG1 - Espanha) ou o de Torre de Palma (POR 2 Portugal). Em BU 1 - Espanha, a propósito de nomes de ventos, não cita Santa Vitória do Ameixial (EVO 2 - Portugal) como paralelo.

Apesar de sabermos quão difícil é a obtenção de fotografias de mosaicos, para as quais são requeridas algumas horas/dias e sucessivas tentativas, para além de iluminação adequada, pensamos que vale a pena a audácia porque imprimem à obra

Conimbriga, 37 (1998) 267-310 
escrita um valioso suporte visual, sempre do agrado do leitor que gosta de acompanhar, amiúde, as linhas de análise e de embrenhar-se na leitura. Um leitor motivado é a maior recompensa para qualquer escritor. Por entre algumas boas fotografias, surgem outras onde a inscrição é de difícil leitura. Algumas cópias ou ampliações de fotos, já publicadas, não surtiram grande efeito, além de outras onde devia ter procedido a arranjos e cortes (na lám. 24b, p. 242, a sapatilha do fotógrafo vê-se no canto da fotografia).

Quanto às inscrições em mosaicos portugueses (COI 1- Conimbriga; EVO 1 a 4 - Santa Vitória do Ameixial; EVO 5 - Tapada do Garriancho; FAR 1- Faro; POR 1 e 2- Torre de Palma; SAN 1- Torres Novas), poucas novidades adianta. A propósito dos antropónimos do mosaico da sala anexa ao oecus-triclinium da, sobejamente conhecida, Casa dos Repuxos, apresenta uma interpretação pessoal do enigmático nome de que nos resta apenas [...]LLVN/C[...]VS. Acredita que, na realidade, se trata de Alluncquius, antroponimo indígena lusitano conhecido. Contesta ainda a leitura CALI/ME[R]VS, que prefere 1er CV/ME/[L]IVS. Quanto ao mosaico situado junto à piscina de Santa Vitória do Ameixial (EVOl), considera-o de carácter cómico, no seguimento de R. Étienne, apontando como paralelo o de Puente Genii (C03 - Espanha). A interpretação segue aproximadamente a de J. d'Encarnação, diferindo na opinião acerca de Cirdalus, que considera uma substantivo com significado de "animal astuto/zorro", bem como na reconstituição da terceira legenda: PRO[FITE]/RESET[T]/VA(s) RE(s) D[ESERIS?]. Concorda com a presença das iniciais de uma oficina no mosaico do átrio de Santa Vitória do Ameixial (EV02), mas desdobra-as de modo diferente: K(olonia) A(ugusta) F\{irma) $l \mathrm{C}$ (aius ?) $\mathrm{T}$ (esselarius) $\mathrm{F}$ (ecif). A outra inscrição da mesma villa (EV03), em caracteres gregos, permanece sem resolução. Em relação ao mosaico de Oceano de Faro (FARI), rejeita a última leitura de J. d'Encamaçâo para o texto em falta na $3^{\text {a }}$ linha TES SELAS $[Q(\ll<$ ?) DE SVO STRAVERjVNT, seguindo antes a reconstituição de J. Alarcão, propondo assim TES SELAS [Q(ue) FACIENDVM CURAR] VNT. Finalmente, dá uma última achega no famoso mosaico dos cavalos de Torre de Palma (POR2): os equónimos Hiberus e Inacus são nomes de rios, respectivamente, o Ebro e um dos rios mais importantes da Argólida.

No que diz respeito às conclusões, esperávamo-las menos contabilísticas e mais qualitativas. De facto, tendo o A. manuseado tanto material epigráfico, estaria com certeza abalizado para lançar o debate sobre inúmeras questões. Obviamente que o objectivo de um corpus é limitado, mas não deixa, por isso, de ser um importante ponto de partida para possíveis trajectos nos vários domínios da pesquisa musiva. Referimo-nos, nomeadamente, ao problema das oficinas, dos mosaicistas, dos encomendantes, da mitologia, e tantas outras vias de investigação de âmbito social, tecnológico, económico, político, etc...

Finalmente, apenas queremos chamar a atenção para os índices, elemento essencial de consulta, que estão incompletos, faltando-lhes os nomes de ventos.

Conimbriga, 37 (1998) 267-310 
Para concluir a nossa análise, não poderemos contestar, apesar das observações que fizemos, o contributo desta obra no domínio linguístico, sem dúvida, um trabalho importante para a clarificação de muitos vocábulos/expressões objecto de discussão há longa data. Tendo em conta as dificuldades inerentes a um material tão heterogéneo, de todos os pontos de vista (cronológico, paleogràfico, estilístico, técnico...), trata-se de uma obra com mérito e útil a quem estuda não só epigrafia, como também o tema musivo ou qualquer outro assunto do âmbito da arqueologia, uma vez que dispõe, a partir de agora, de um corpus onde poderá buscar linhas de investigação, gerais ou parcelares, sobre os mais variados assuntos do vasto mundo proporcionado pelos mosaicos romanos.

CRISTINA F. DE OLIVEIRA

Conimbriga, 37 (1998) 267-310 